\title{
The impact of the Jacques Cartier bridge illumination on the food chain: from insects to predators
}

\author{
S. Nankoo*, S. Raymond and R. Galvez-Cloutier \\ Laval University, 2325 University Street, Quebec City, Quebec, Canada, G1V 0 A6 \\ *Corresponding author: E.mail: shivia.nankoo@gmail.com
}

Keywords: Artificial light; Behaviour; Bird; Entomology; Food web; Urban light.

\begin{abstract}
Artificial light at night can impact numerous diurnal species by influencing their distribution and habits. In this study, artificial lights placed on the Jacques Cartier bridge in Montreal, Canada were evaluated to determine their impact on insects, insectivorous birds and peregrine falcons. The impact was measured the year the illumination begun and the year following (two years in total). Insect distribution and abundance at three different sites around the bridge was measured. Insectivorous bird abundance and activity were evaluated by observing the cliff swallow as a proxy. Peregrine falcon presence and nesting behavior at the bridge was measured. Insects (aerial and aquatic) were found to be more abundant closer to the illuminated part of the bridge and particularly in the year following the illumination's beginning. Similarly, cliff swallows were more abundant at the bridge the year following the start of the illumination and their activity was more important closer to the illuminated section. Peregrine falcons were only present at the bridge in the year following the beginning of the illumination and specifically at the illuminated part of the bridge. No nesting was detected. These three groups are connected to each other through a food chain in which insect abundance impacts insectivorous bird abundance, which in turn impacts peregrine falcon presence. The illumination therefore positively impacts these three groups separately and together through their food chain. This research highlights the importance of monitoring bird and insect population close to the bridge and further continuation of these observations are necessary to determine if the observed tendency will continue to develop throughout the years.
\end{abstract}

Abbreviations: DDT-Dichlorodiphenyltrichloroethane; JCCBI-Jacques Cartier and Champlain Bridges Incorporated; LEDLight emitting diode; m-meters; SEF-Services Environnementaux Faucons.

\section{Introduction}

In May 2017, artificial lights of multiple colours and shapes were added on the Jacques Cartier bridge in Montreal, Canada. This urban light is susceptible to have impacts on the organisms that live close to the bridge or use it for nesting or hunting. Insects are an integral part of this group. They form the largest taxonomic group in the world in terms of species and biomass and there are 25000 species in Quebec of which only 13000 have been identified (Bélanger 1991). Quebec insects mostly live in forests, wetlands and lakes but an important abundance of insects is often seen in urban environments due to the presence of artificial light (Robinson 2005, Bélanger 1991).

Exposure to artificial light can have important detrimental effects on insects. Artificial light can hinder the detection of light signals sent between individuals for reproduction, reducing their ability to detect each other and potentially hindering their reproductive success (Eisenbeis and Hänel 2009, Owens and Lewis 2018). Moreover, attraction to light sources at night increases their chance of being preyed upon and their risk of being tired or burned, both of which can result in their deaths (Eisenbeis and Hänel 2009, WSP 2016, Owens and Lewis 2018, Egri et al. 2017).

The present article evaluates the impact of artificial light on insects living close to the Jacques Cartier bridge in terms of their distribution and their abundance at different distances from the bridge. Moreover, a predator species, the peregrine falcon (Falco peregrinus Tunstall), was also observed. Data collection was used to determine its presence at the bridge, its nesting habit and its different observed behaviors (hunting, nesting, feeding, etc.). The cliff swallow (Petrochelidon pyrrhonota Vieillot) was similarly observed to determine its abundance and distribution on the bridge to use as a proxy for insectivorous bird presence. These three organisms were then connected to each other to conclude that they are part of a food chain in which predators feed on insectivorous birds which in turn feed on insects.

The predator species studied in this research is the peregrine falcon. It is one of the most studied bird species in the world (Davis 2008). In Quebec, its presence is noted from 
Montreal to the North of the province (Brûlotte 2000). The falcon is a migratory bird that feeds on birds and small mammals (CRFPQ 2002). In natural environments, it nests on high and rocky mountain surfaces. In urban environments, individuals nest on top of high buildings and bridges (COSEPAC 2007, Hémisphère 2011, Brûlotte 2000). Their nesting period lasts from mid-March to August (Molina et al. 2016). Large open spaces are preferred to facilitate hunting. Tall buildings are ideal nesting areas for falcons since there is often an important presence of prey birds like pigeons. (Davis 2008). The falcon is a diurnal bird (COSEPAC 2007).

This study focused on a short (2 years) temporal and spatial comparison in insect and bird abundance on the Jacques Cartier bridge since only little past data is available for peregrine falcons and no data is available for insects.

\section{Methods}

All observations (for falcons, swallows and insects) were done during the summer from April to August, anytime during the day, in 2017 and 2018.

\section{Insects}

Three sample sites for measuring insect abundance were chosen for their varying distances from the Jacques Cartier bridge's illuminated section. The three sites are shown in Figure 1.

The first site is the control zone. At this site, the illuminated section of the bridge is not visible. Insects at this site should therefore not be affected by the artificial lights. This site is located close to the Marie-Victorin Park in Longueuil. The second site is the intermediate zone. This site was changed location between 2017 and 2018 due to theft and breakage of insect traps. In the first year of the study, it was located behind the police station at 977 Pierre-Dupuy street in Longueuil. In 2018, the site was located on the North of Saint Helen's Island in the La Ronde amusement park parking lot. The illuminated section of the bridge is visible at this site, but the distance (more than $1 \mathrm{~km}$ ) allows only a limited impact on the insect population. The last site is the illuminated zone. This zone is located right under the illuminated portion of the bridge and insects in this area are expected to be highly influenced by the artificial lights. It is located on the Western shore of Saint Helen's Island, next to the La Ronde amusement park.

Six insect traps were installed at each site: three for capturing flying terrestrial insects and three for catching emerging aquatic insects (Fig. 2).

All traps were installed and kept on location for a week (from Monday to Friday). This was done twice each summer: in July and August. In total, 18 traps were installed each week and insects were collected from the traps every two days. Samples were kept in propylene glycol until analysis. Insect were placed in petri dishes and were counted manually by totalling the number of intact cephalothoraxes.

\section{Cliff swallows}

Cliff swallow abundance and distribution were determined by counting the number of nests on the bridge and evaluating the number of active and inactive nests. Nests were manually counted on the complete bridge and at each section of the bridge. Evaluation of nest activity was done by observing each detected nest until bird activity was detected inside the nest (maximum 30 minutes).

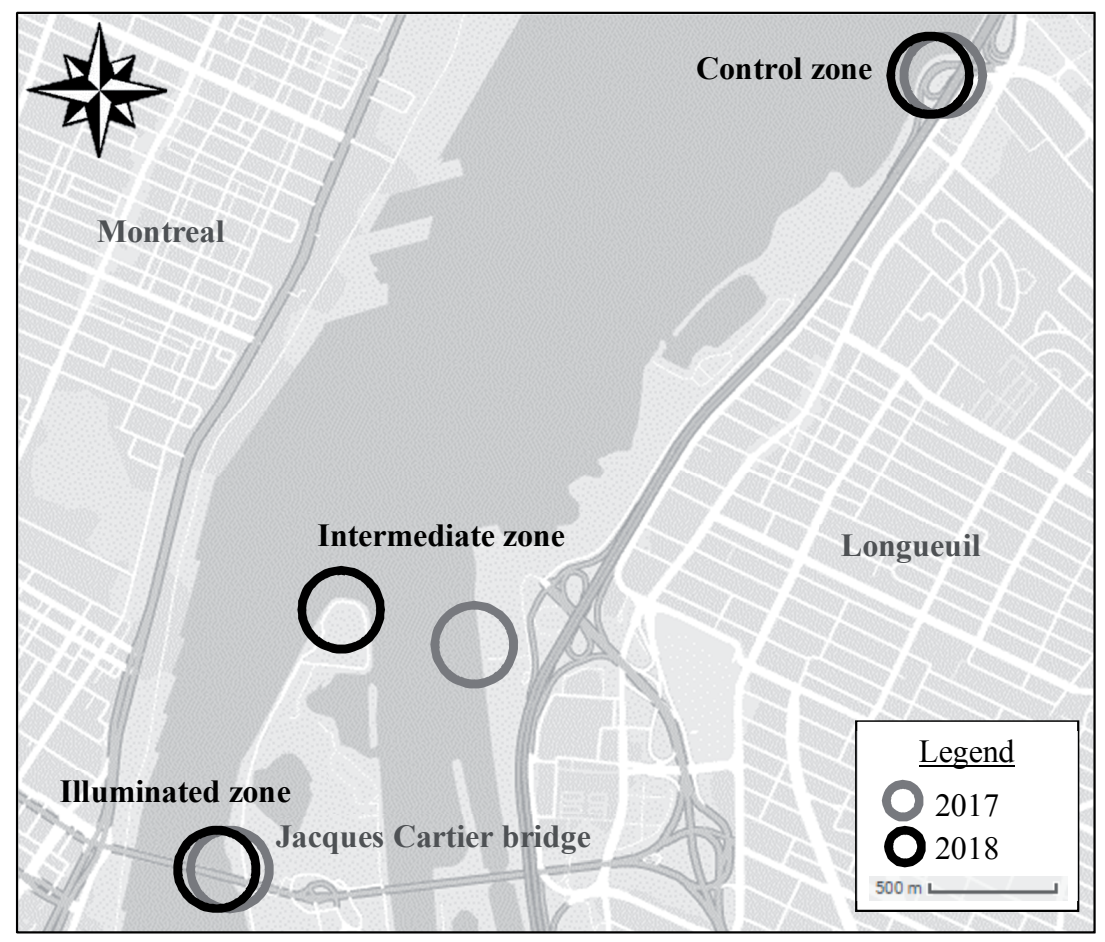

Figure 1. Location of the three sites for insect capture in proximity to the Jacques Cartier bridge. The light gray circles represent the study sites in 2017 and the black ones in 2018 . 


\section{Peregrine falcons}

Three times each week for the whole summer, pillars 24 and 25 (Section 7) of the Jacques Cartier bridge were observed to detect any falcon presence (Fig. 3). Each observation lasted three hours and every behavior exhibited by the falcon individuals were recorded as well as their frequency. Behaviors included among others: grooming, resting, flying, hunting and communication. Observations were lengthened to four hours when nesting was suspected (SEF 2017).

\section{Results}

All data collected following the observation of insects, cliff swallows and peregrine falcons at the bridge were analysed. The results for each group of organisms studied are presented in the following figures.

Insects

Figure 4 demonstrates insect abundance at each study site for the two study years (2017 and 2018). Abundance was measured by totalling the number of insects present in each sample and dividing this total by the area/volume covered by each trap.

On the first collection week of 2017, there is a highest abundance of insects at the control site for both terrestrial and aquatic insects: around 700 for aerial traps and 2100 for aquatic traps. The intermediate site follows closely with 400 insects for terrestrial traps and 1500 for aquatic traps. Finally, the illuminated site has the lowest insect abundance: around 200 insects for aerial traps and 1000 for aquatic traps.

On the second week of 2017, the number of captured insects at the intermediate site decreases slightly whereas it increases slightly at the illuminated site. The control site remains the one with the highest abundance for the aquatic traps. However, for the aerial traps, the illuminated site is the one with the highest insect abundance (300 insects compared to 100 at the intermediate site and 200 at the control site).

Results for the second year of the study greatly differ from 2017. The highest insect abundance is found at the illuminated site for aerial traps: around 500 on the first week and 800 on the second. As for aquatic traps, the first week of 2018 shows that the control site has a higher insect abundance (around 900 insects compared to 600 at the illuminated site). However, the illuminated site contains the most insects on the second week of 2018 with an abundance value of 1200 insects per $\mathrm{m}^{2}$

Figure $4 \mathrm{a}, \mathrm{b}$ and c clearly demonstrate the increasing abundance of terrestrial insects at the illuminated site over the two study years. Furthermore, the decrease in insects at the control site is also highlighted. The tendency detected at the illuminated site could potentially result from the exposure to artificial light since abundance increases following the second half of the summer of 2017, right after the illumination begun in May 2017. An ANOVA statistical test reveals that insect abundance in 2017 is not significantly different from one site to another $(\mathrm{p}=0.732)$. However, insect abundance in 2018 is significantly different between sites $(\mathrm{p}=0.035<$ 0.05), confirming that the illumination might be responsible for this tendency since the most significant impact is seen in a)

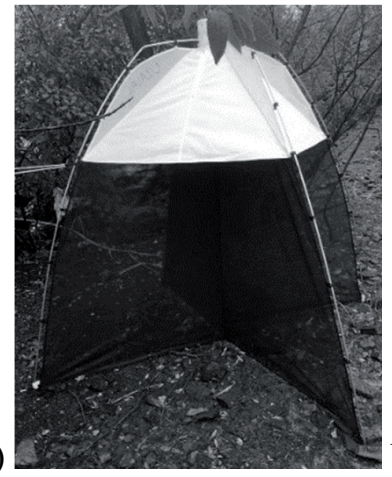

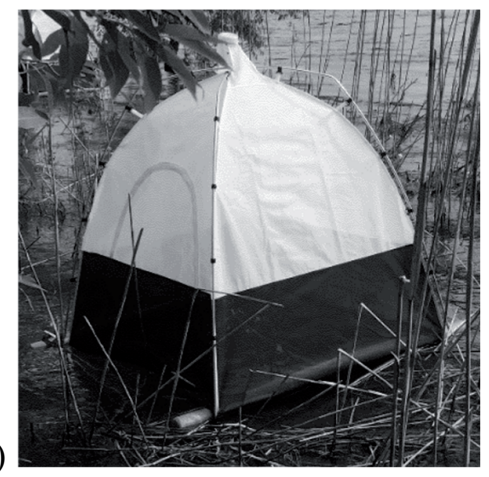

Figure 2. Pictures of the two types of insect traps used in this experiment: a) Aerial trap (MegaView Science Co. SLAM Trap Large BT1005 and b) Emergence trap (MegaView Science Co. Amphibious Emergence Trap BT2008).

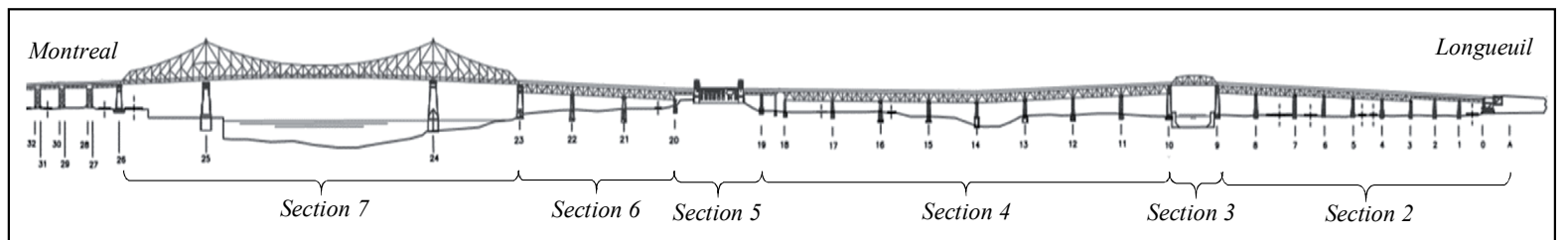

Figure 3. Location of the sections on the Jacques Cartier bridge. The peregrine falcon observation site is located in section 7 (sourced from Jacques Cartier and Champlain Bridges Incorporated (JCCBI)). 
a)

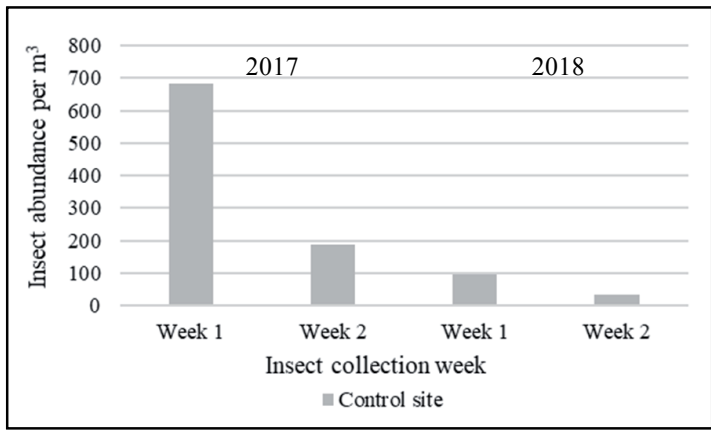

c)

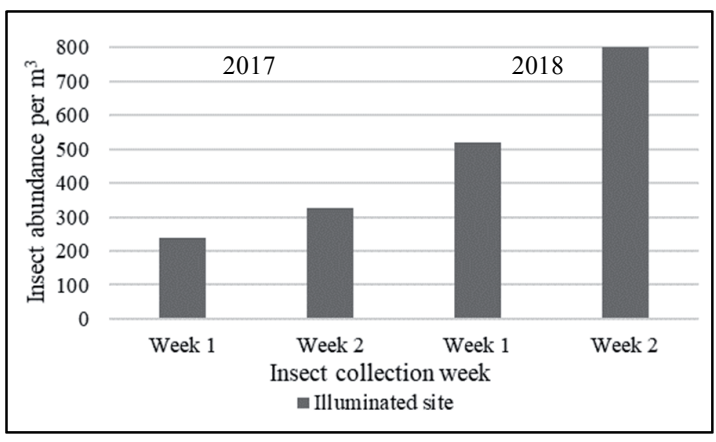

e)

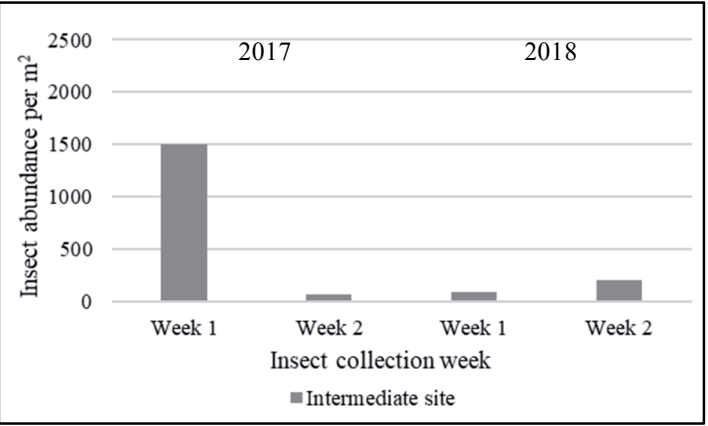

b)

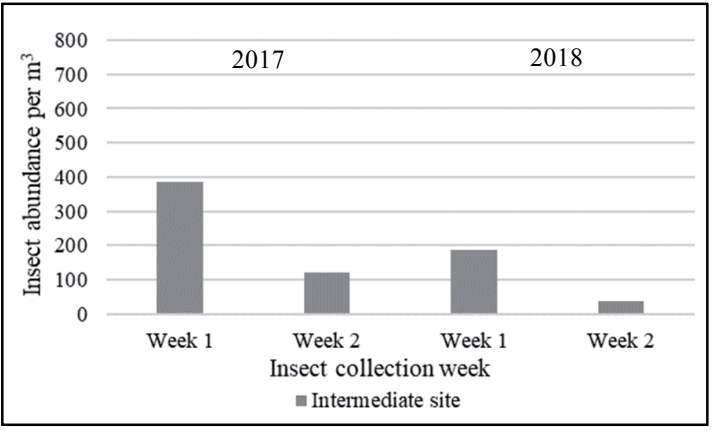

d)
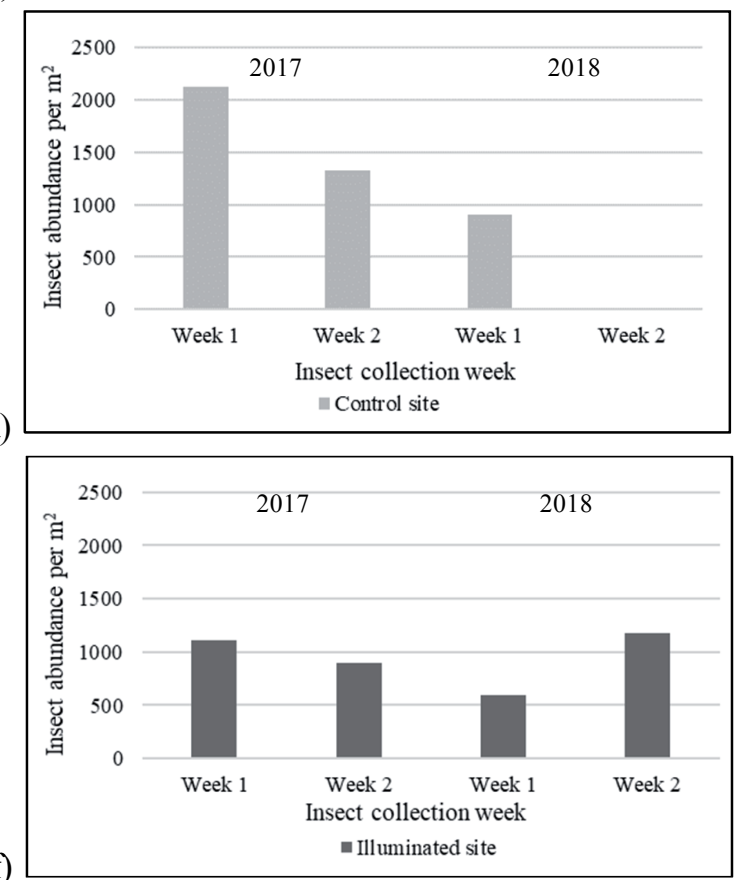

Figure 4. Insect abundance at the Jacques Cartier bridge in 2017 and 2018 per $^{3}$ for aerial traps at a) the control site, b) the intermediate site and c) the illuminated site, as well as insect abundance per $\mathrm{m}^{2}$ for aquatic traps at $\mathrm{d}$ ) the control site, e) the intermediate site and f) the illuminated site. Loss and breakage of traps might cause discrepancies in the data.

the year following the installation of the artificial lights. The same observation can be seen for the aquatic traps (Figs. $4 \mathrm{~d}$, e and $\mathrm{f}$ ), but the intensity is lesser than for the aerial traps. In fact, an ANOVA statistical test reveals that there is no significant difference between insect abundances at the three different sites for either study year (2017: $p=0.451$ and 2018: $p$ $=0.363$ ). Boat passage and high wind at the illuminated site caused most aquatic traps to often fall, which could have lessened the number of insects captured at this site. This could explain why aquatic insect abundance did not show the same impact from light as terrestrial insects.

\section{Cliff swallows}

Results from cliff swallow observations are summarized in the following figures.

Figure 5 shows that the abundance of cliff swallow nests was highest in the second year of the study (2018). Although the number of nests seems to continually increase since 2015, nest abundance is significantly higher in 2018 , the year following the beginning of the illumination. This observation supposes that the illumination had a positive impact on cliff swallow abundance on the bridge.

Figure 6 demonstrates that nest activity has increased from 2017 to 2018 at the sections closest to the bridge's illumination. In fact, sections 6 and 7 had low abundance and percentage of active nests in 2017 but these values highly increased in 2018, the year following the installation of the lights. This suggests that the illumination had a positive impact on cliff swallow activity and nest distribution on the illuminated section of the bridge.

\section{Peregrine falcons}

In 2017, two falcons were seen hunting in section 7 of the Jacques Cartier bridge. This was the only notable observation of peregrine falcons in the first year of the study.

In 2018, two falcons were seen on a daily basis on pillar 25 of the Jacques Cartier bridge. Multiple hunting and flying behaviors were detected reinforcing the idea that the bridge was part of their territory. Communication between the two 
Figure 5. Cliff swallow nest abundance from 2012 to 2018. The first year of the study (2017) is shown in medium gray and the second year (2018) is shown in black. Results from 2012 to 2016 were taken by Services Environnementaux Faucons (SEF) and are shown in light gray.

Figure 6. Percentage of activity and abundance in parentheses of cliff swallow nests at each section $(2,3,4,5,6$ and 7$)$ of the Jacques Cartier bridge in a) 2017 and b) 2018.
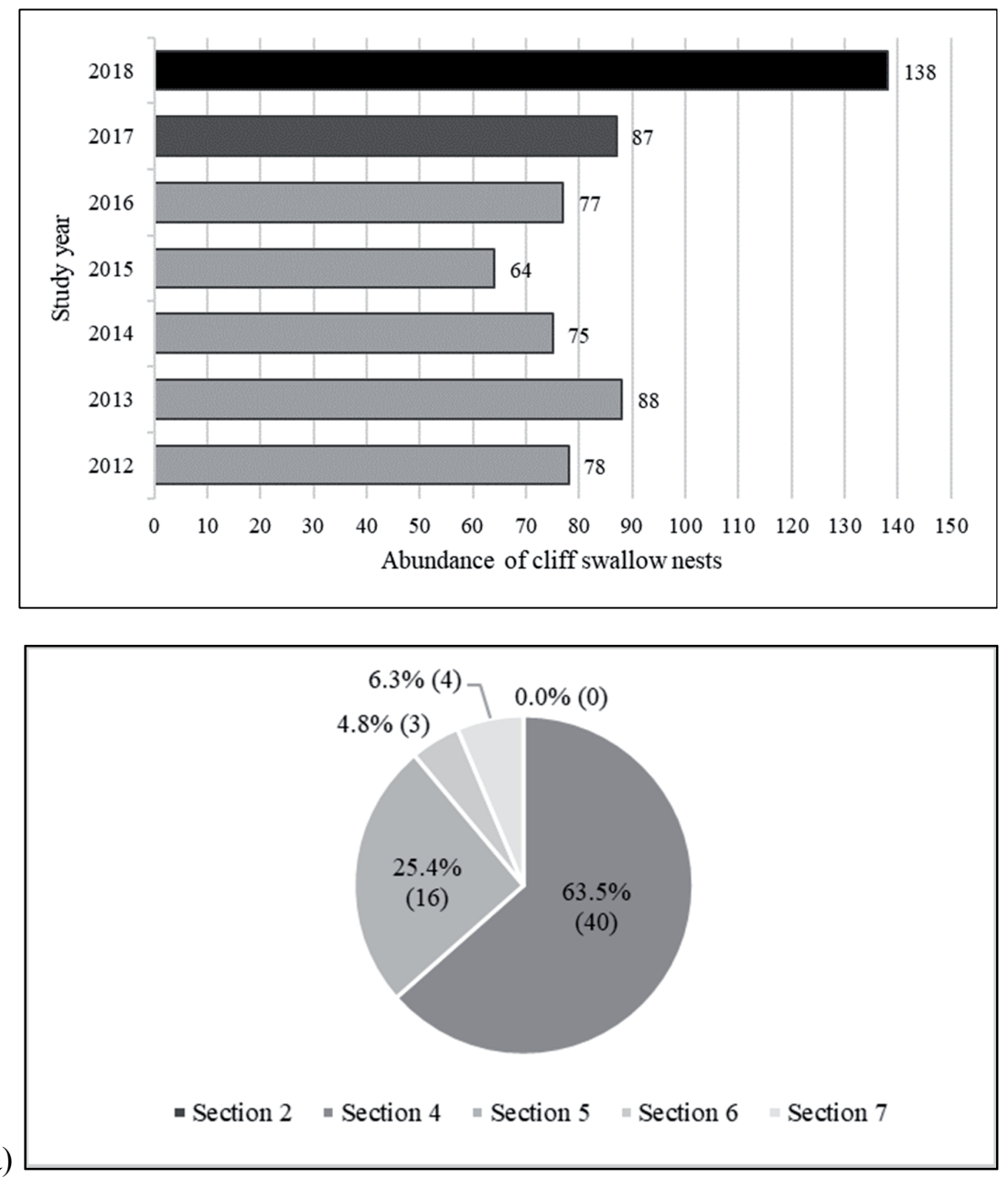

a)

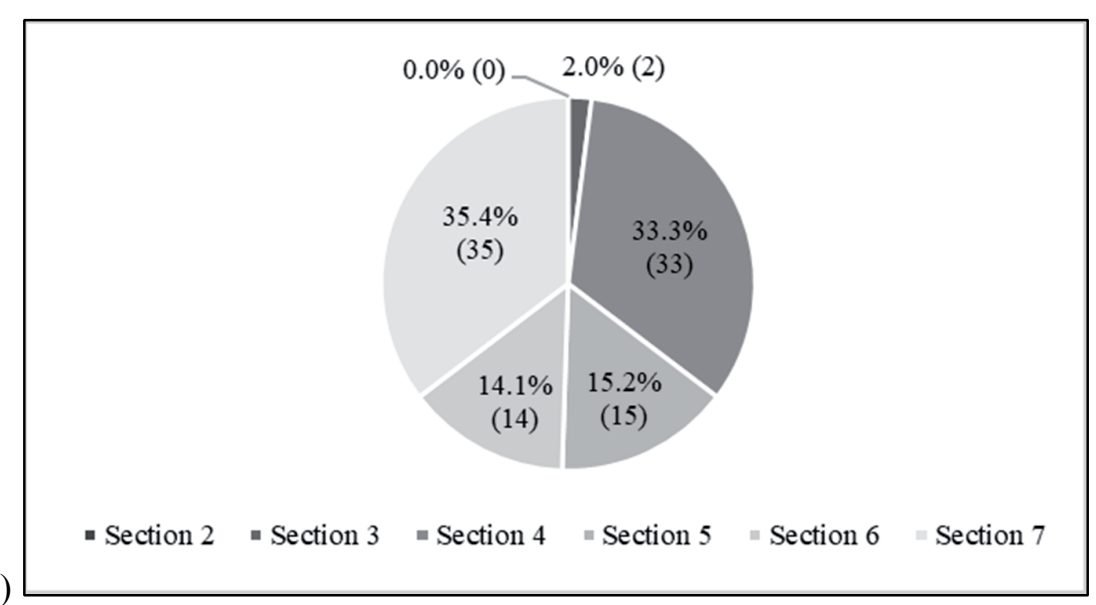

birds suggested that they were a breeding couple. Later in the summer juvenile birds were seemingly heard on the Eastern side of the bridge, between pillars 23 and 24. However, an inspection of the area showed no nest. Predation traces were however detected (discarded food items for future consumption).

Therefore, no nesting behavior was detected in 2017 nor 2018. Figure 7 summarizes the main results of the second study year in terms of falcon behaviors (limited data was col- lected in the first year since no significant falcon presence was detected).

Data shows that the most important behavior noticed in the bird couple was resting (seen $40.6 \%$ of the time) followed closely by flying (31.9\%). These behaviors are signs that the Jacques Cartier bridge was part of the falcons' territory. Behaviors like grooming, communication, hunting, feeding, vocalisations and aggression were also detected at lower percentages than flying and resting. Copulation and 


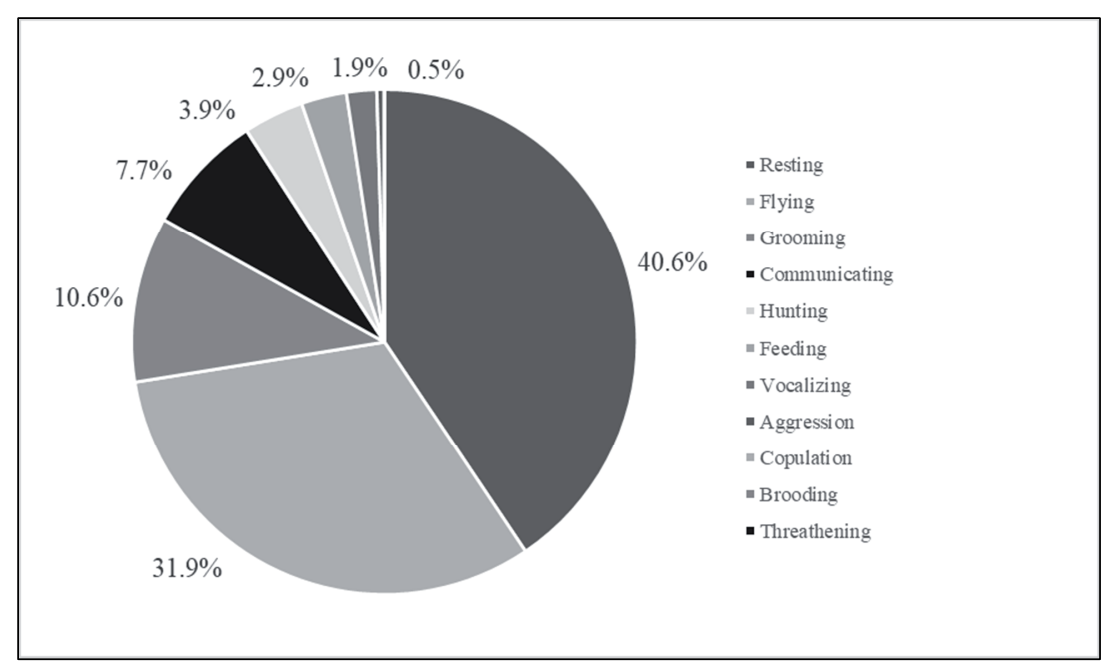

Figure 7. Percentage occurrence of peregrine falcon behaviors observed in 2018 at the Jacques Cartier bridge.

brooding behaviors were not observed, confirming that no nesting occurred in 2018. Falcons were furthermore never seen threatening.

\section{Discussion}

Insect abundance data shows that for aquatic traps, abundance is highest at the control site than at the illuminated site for the first and second collection weeks of 2017 and the first week of 2018. For the second week of 2018, insect abundance is highest at the illuminated site. This doesn't allow for any conclusion on the impact of the illumination since high insect abundance near the illumination was only seen once. Moreover, this spatial comparison (compared to a preferable temporal comparison, which was impossible considering the lack of past data on insect populations in Montreal) is too limited to make a precise conclusion.

Terrestrial traps show a gradually increasing insect abundance at the illuminated site from the first to last collection week. From the second week of 2017, the number of captured insects at the illuminated site increases more and more at each collection week. This tendency could suggest that the illumination is partly responsible for this increase in abundance. Moreover, the first reproduction cycle of insects in 2017 (every three months) took place before the artificial lights were installed in May. Therefore, this explains why the impact of the illumination would only be seen after this period, on the second week of 2017.

Insects are known to be attracted to artificial light sources. Studies have shown that insects are highly attracted to incandescent lights: sodium or mercury (McDonnell et al. 2015, Justice and Justice 2016). These two types of light are used as lamp posts on the bridge. The added artificial lights are LEDs, which can in some cases have a more important attractive power than incandescent lights (Pawson and Bader 2014, Egri et al. 2017). Moreover, the added attraction could have intensified the insect response and therefore increased abundance close to the bridge.

This attraction could have encouraged insectivorous birds like cliff swallows to nest in proximity to areas of high insect attractiveness. Cliff swallows depend highly on aerial insects to feed and any decrease in their abundance can lead to catastrophic population declines (ICOAN 2012). Habitat destruction and fragmentation (especially in wetlands), excessive pesticide usage and pollution are responsible for the present decline in insect populations (Arnett 2000). Therefore, an increase in their abundance could lead to an increase in cliff swallows in the same area. Moreover, a brief identification of trapped insects showed that the most common insect order found in aerial and aquatic traps was Diptera. This insect begins its life in an aquatic state and emerges as an adult to become a terrestrial insect. As an adult individual, it is an important part of the diet of insectivorous birds, which might have encouraged the latter to be more present at areas where it is found.

Observations seem to confirm this. This suggests that an increase in insect abundance might be the cause for the cliff swallow distribution on the bridge. Since there are many other insectivorous birds present on the bridge other than $P$. pyrrhonota (the common starling Sturnus vulgaris L., the Northern rough-winged swallow Stelgidopteryx serripennis (Audubon), the Common grackle Quiscalus quiscula (L.)as well as the feral pigeon Columba livia domestica Gmelin) (WSP 2016), the same hypothesis can be applied to these species: a greater insect abundance will lead to an increase in bird abundance. The peregrine falcon, in the same way as these species, can profit from this increase in prey and be more present at the bridge.

Falcon nests were previously detected on the Jacques Cartier bridge in 2005, 2008, 2009, 2010 and 2011. Although no nests were detected between 2011 and 2016, falcons were still seen on several occasions flying and hunting around the bridge (Molina et al. 2015, Molina et al. 2016). In the first year of this study, one falcon was seen flying with a prey in its claws. 2018 was the most significant year in terms of falcon presence since a couple was seen every observation day on the illuminated section of the bridge. Moreover, behaviors like flying and hunting were seen very often, confirming that the falcons might take advantage of its position at the bridge to hunt.

This observation seems to coordinate with a highest number of preys at the bridge, translated from a higher abundance 
of cliff swallows which are not part of a falcon's diet but mirror the effect of increased abundance of insectivorous birds at the bridge.

Literature has shown that falcons take advantage of artificial light to facilitate their prey catch. Multiple nocturnal migratory birds can be disoriented by the presence of artificial light sources and fly around them in circles, making them more vulnerable to predation (Longcore and Rich 2004, Stone 2018, Kociolek et al. 2011, Squires and Hanson 1918, Merkel and Johansen 2011, Avery et al. 1976, Poot et al. 2008). DeCandido and Allen (2006) have shown that in New York, peregrine falcons benefit from this vulnerability to hunt on these specific preys. Tall buildings are an important component of their hunting location since they can easily perch themselves above migratory birds and hunt them more easily. The presence of falcons at the Jacques Cartier bridge is understandable considering that the bridge is also very high. Other studies have shown falcons are often seen hunting at night in areas where there is artificial light (Marconot 2003, Wendt et al. 1991, Drewitt and Dixon 2008). The artificial light on the bridge could therefore encourage falcons to hunt.

It is difficult to precisely determine whether the illumination is responsible for this increased presence of falcons at the bridge since it was only detected once (in 2018). However, a high presence of preys could potentially explain this observation. Predation traces were found on the bridge, confirming that the falcons use this area to hunt. This evidence was not found in 2017. Therefore, the illumination could be indirectly responsible for the falcons' presence.

As mentioned previously, there was no nesting on the Jacques Cartier bridge in 2017 nor 2018. This could be the consequence of different factors. The presence of a common raven (Corvus corax L.) nest on the bridge between pillars 10 and 11 on Notre-Dame Island could discourage falcons from nesting at this area since competition could arise between the two species. Although artificial nests were installed and used in previous years by other peregrine couples, an evaluation done by Molina et al. (2011) found multiple problems that could discourage falcons from using the nests now. First, there are no rocks on the floor of the nest which are important for the female to lay her eggs on. Without rocks, the female could be deterred from using the nest. Second, the mat installed at the front of the artificial nest is not secured. This means that the corners of the mat can move with the wind and scare any bird wanting to enter the nest. Third, rain events can trigger water to drip inside the nest and mold can form (Molina et al. 2015).

The peregrine falcon population of Canada had greatly decreased due to the usage of pesticides like DDT. The pesticide was since banned and efforts were done to increase population numbers. Multiple artificial nests were installed in Montreal to encourage nesting and some individuals raised in captivity were released (Hémisphère 2011, Vuilleumier 2009, CRFPQ 2002). In 2010, 59\% of falcon nests found in Quebec were found in natural habitats, $19 \%$ in quarries, $10.5 \%$ on buildings and $11.5 \%$ on bridges (Tremblay et al.
2012). Falcons will reuse the same nests many years in a row (COSEPAC 2007, Davis 2008). Juveniles will also come back to the place they were born to nest (Bird 1997). This shows the importance of encouraging peregrine falcons to nest on the Jacques Cartier bridge and to protect their nesting area to insure the survival of the Montreal population. At the moment, the falcon population is stable (Davis 2008, Vuilleumier 2009).

Therefore, the illumination has a potentially positive impact on the presence of peregrine falcons in proximity to the bridge but its impact on nesting behavior is still unknown.

The data collected in the two years of this study have shown an increase in insect and cliff swallow abundance, and peregrine falcon presence close to the illuminated section of the Jacques Cartier bridge. These observations can potentially be linked to each other by considering that these three species are part of the same food chain in this ecosystem (Fig. 8). In fact, as hypothesized previously, the artificial lights can attract more insects towards the bridge, which in turn attract more insectivorous birds to the bridge (the cliff swallow, among others). This abundance of birds can encourage the presence of the peregrine falcon at the bridge.

This hypothesis is not confirmed considering that no past data is available on insect distribution before the illumination started and that this study only lasted two years. Further continuation of the study needs to be done to confirm this tendency. Further observations could show that birds get accustomed to artificial light and impacts seen in this study disappear after a few years of light exposure. In fact, most studies focus on short-term impacts of artificial light and lack the long-term response of birds. Studies that do observe long-term impacts in the laboratory show that the impacts observed (for example, increase in heart rate) tend to be less pronounced after prolonged exposure (Lustick 1973, Yorzinski et al. 2017). In this study, bird distribution and activity could return to normal, that is, to a distribution of cliff swallow nests on the bridge or an activity rate that has nothing to do with the presence of artificial lights on Section 7.

Results for insects have shown an increase in abundance closer to the bridge and a decrease farther from the bridge. This could suggest that a displacement of insect populations around the Jacques Cartier bridge was happening due to light exposure. In other words, insects far from the bridge could be moving towards it and from one generation to another, insect abundance has grown closest to the bridge. This decreased abundance could be detrimental to animals relying on insects in the sites farthest from the bridge. This hypothesis would need to be confirmed after long-term light exposure.

\section{Conclusion}

The first year of the study has shown little to no impact on the studied species. This is to be expected since the illumination was not in place when the peregrine falcon or the insects arrived at the bridge. There is a slight increase in aerial insects at the end of 2017. 

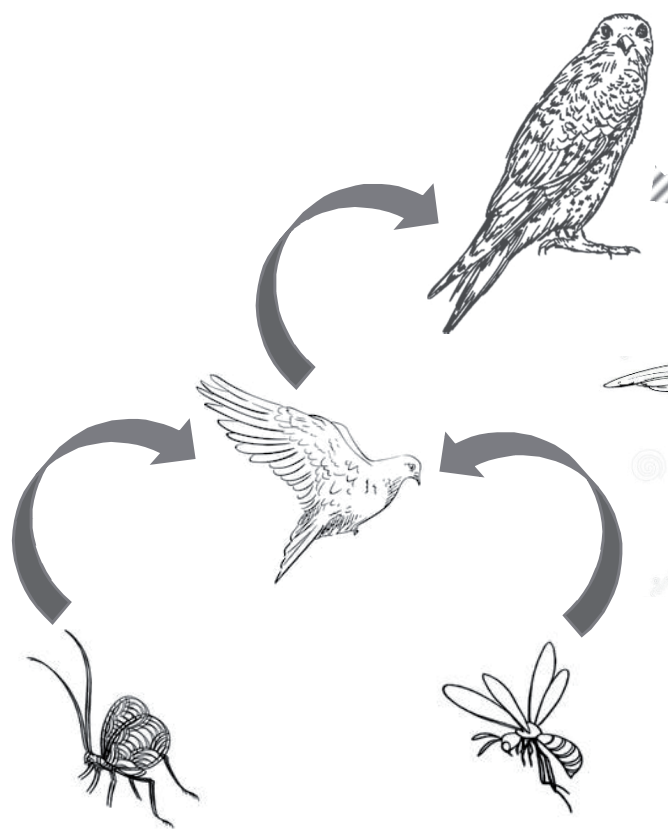

Following the second year of the study, effects of the illumination were visible on insects and falcons alike. The artificial lights were already in place when the species arrived from their migration. Data has shown that a record number of cliff swallow nests was detected in 2018 and that this increase is mostly located in areas close to the illumination of the bridge. Although other factors might be responsible for this observation, the artificial lights on the bridge could play an important role. This tendency for cliff swallows to choose to nest close to the illumination might be explained by a high abundance of insects attracted to the lights. This was confirmed with this study as a higher abundance of flying insects was found in the site closest to the illumination compared to farther sites. This increase in cliff swallows can potentially show that insectivorous birds are more abundant close to the bridge's artificial lights. This amplified presence seems to encourage top predators like the peregrine falcon to hunt in this area. This was also confirmed with this study since a notable falcon presence was noted in 2018 compared to 2017 .

These observations suggest that the presence of the illumination on the bridge reinforce the trophic chain linking insects, insectivorous birds and top predators.

Further observations need to be done in order to confirm both the increase in insect abundance and the presence of peregrine falcons close to the artificial lights of the Jacques Cartier bridge. The conclusions found in this study are preliminary considering that observations were only made for two years and no previous data is available on insect distribution.

Acknowledgements: The authors wish to thank Jacques Cartier and Champlain Bridges Incorporated (JCCBI) for their financial and technical support, as well as their assistance for accessing the study sites.
Figure 8. Diagram of the food chain connecting insects, insectivorous birds (including the cliff swallow) and peregrine falcons (the top predator species). Full arrows show a direct impact and dotted arrows show an indirect impact.

\section{References}

Arnett, R.H. 2000. American Insects: A Handbook of the Insects of America North of Mexico. 2nd Edition. CRC Press, Boca Raton.

Avery, M., P.F. Springer and J.F. Cassel. 1976. The effects of a tall tower on nocturnal bird migration: a portable ceilometer study. AOS 93:281-291.

Bélanger, P. 1991. Analyse de 50 espèces d'insectes en situation précaire au Québec et problématique de gestion. Société d'entomologie du Québec. Ministère du Loisir, de la Chasse et de la pêche du Québec. Direction de la gestion des espèces et des habitants.

Bird, D.M. 1997. Rapport sur la situation de faucon pèlerin (Falco peregrinus) au Québec. Ministère de l'Environnement et de la Faune, Direction de la faune et des habitats.

Brûlotte, S. 2000. Les oiseaux du Québec: guide d'initiation. Broquet Inc. $2 \mathrm{e}$ édition. Ottawa.

Comité de rétablissement du faucon pèlerin au Québec (CRFPQ). 2002. Plan d'action pour le rétablissement du faucon pèlerin anatum (Falco peregrinus anatum) au Québec. Société de la faune et des parcs du Québec.

COSEPAC. 2007. Évaluation et Rapport de situation du COSEPAC sur le Faucon pèlerin (Falco peregrinus) de la sous-espèce pealei (Falco peregrinus pealei) et anatum/tundrius (Falco peregrinus anatum/tundrius) au Canada - Mise à jour. Comité sur la situation des espèces en péril au Canada, Ottawa.

Davis, K. 2008. Falcons of North America. Mountain Press Publishing Company. Missoula, Montana.

DeCandido, R. and D. Allen. 2006. Nocturnal hunting by peregrine falcons at the Empire State Suilding, New York City. Wilson J. Ornithol. 118(1):53-58.

Drewitt, E.J.A. and N. Dixon. 2008. Diet and prey selection of urbandwelling Peregrine Falcons in southwest England. Brit. Birds 101(2):58-67.

Egri, Á., D. Száz, A. Farkas, Á. Pereszlényi, G. Horváth and G. Kriska. 2017. Method to improve the survival of night-swarming mayflies near bridges in areas of distracting light pollution. $R$. Soc. Open Sci. 4:171166.

Eisenbeis, G. and A Hänel. 2009. Light pollution and the impact of artificial night lighting on insects. In: M.J. MacDonnell, 
A.K. Hahs and J.H. Breuste (eds.), Ecology of Cities and Towns: A Comparative Approach. Cambridge University Press, Cambridge. pp. 243-263.

Hémisphère, G. 2011. Potentiel de nidification et inventaire estival de l'avifaune utilisant les habitats des propriétés de PJCCI. Rapport produit pour Les Ponts Jacques Cartier et Champlain Inc.

Initiative de conservation des oiseaux de l'Amérique du Nord (ICOAN). 2012. État des populations d'oiseaux du Canada, 2012. Environnement Canada, Ottawa, Canada.

Justice, M.J. and T.C. Justice. 2016. Attraction of insects to incandescent, compact fluorescent, halogen, and LED lamps in a light trap: implications for light pollution and urban ecologies. Entomol. News 125:315-326.

Kociolek, A.V., A.P. Clevenger, C.C. St. Clair and D.S. Proppe. 2011. Effects of road networks on bird populations. Conserv. Biol. 25 (2):241-249.

Longcore, T. and C. Rich. 2004. Ecological consequences of artificial night lighting. Front. Ecol. Environ. 2:191-198.

Lustick, S. 1973. The effects of intense light on bird behavior and physiology. Bird Control Seminars Proceedings 119:171-186.

Marconot, B. 2003. Comportement de chasse nocturne du Faucon pèlerin Falco peregrinus à Belfort. Ornithos 10(5):207-211.

McDonnell, MJ., A. H. Hahs and J.H. Breuste. 2015. Ecology of Cities and Towns. Cambridge University Press, Cambridge.

Merkel, F.R. and K.L. Johansen. 2011. Light-induced bird strikes on vessels in Southwest Greenland. Mar Pollut Bull 62:2330-2336.

Molina, P., Skelling, M.G., Lecours, J. and A. Laperrière. 2011. Rapport sur l'évaluation des nids de Faucon pèlerin sur les ponts fédéraux et les recommandations en vue d'amélioration. Services Environnementaux Faucons Inc., Montréal, Québec (Canada).

Molina, P., Skelling, M.G., Allard, M. and Graham-Sauvé, L. 2015. État de la nidification du faucon pèlerin et de l'hirondelle à front blanc en 2014 sur les structures de PJCCI et recommandations de gestion pour 2015. Services Environnementaux Faucon Inc., Montréal, Québec (Canada).

Molina, P., M.G. Skelling, L. Graham-Sauvé, M. Fiola, A. Belzile and M. Allard. 2016. État de la nidification du Faucon pèlerin et de l'Hirondelle à front blanc en 2016 sur les structures de PJCCI et recommandations de gestion pour 2017. Rapport produit pour Les Ponts Jacques-Cartier et Champlain Inc.

Owens, A.C.S. and S.M. Lewis. 2018. The impact of artificial light at night on nocturnal insects: a review and synthesis. Ecol. Evol. 8(22):11337-11358.

Pawson, S.M. and M.K.-F. Bader. 2014. LED lighting increases the ecological impact of light pollution irrespective of color temperature. Ecol. Appl. 24(7):1561-1568.

Poot, H., B.J. Ens, H. de Vries, M.A.H. Donners, M.R. Wernand and J.M. Marquenie. 2008. Green light for nocturnally migrating birds. Ecol. Soc. 13(2):47

Robinson, W.H. 2005. Urban Insects and Arachnids: A Handbook of Urban Entomology. Cambridge University Press. Cambridge, UK.

Services Environnementaux Faucon (SEF). 2017. Protocole d'observation du Faucon pèlerin. Services Environnementaux Faucon, St-Lazare, Québec (Canada).

Squires, W.A. and H.E. Hanson. 1918. The destruction of birds at the lighthouses on the coast of California. Condor 20:6-10.

Stone, T. 2018. The value of darkness: a moral framework for urban nighttime lighting. Sci. Eng. Ethics 24(2):607-628.

Tremblay, J., P. Fradette, F. Shaffer and I. Gauthier. 2012. Inventaire quinquennal 2010 du faucon pèlerin au Québec méridional : état de la population québécoise. Nat. Can. 136(3):88-93.

Vuilleumier, F. 2009. Birds of North America. DK Publishing. 1e edition. New York.

Wendt, A., Septon, G. and J. Moline. 1991. Juvenile urban hacked peregrine falcons (Falco peregrinus) hunt at night. J. Raptor Res. 25(3):94-95.

WSP. 2016. Mise en lumière du pont Jacques-Cartier: évaluation des effets environnementaux, Montréal, Québec. Rapport produit pour Les Ponts Jacques Cartier et Champlain Incorporée. No projet :151-11367-00.

Yorzinski, J.L., K. A. Ordonez and K.T. Chema. 2017. Does artificial light pollution impair problem-solving success in peafowl? Ethology 123:854-860.

Received March 29, 2019 Revised June 5, 2019 Accepted July 3, 2019 